\title{
Ketersediaan dan Serapan Mg Kacang Tanah Alfisol dengan Abu Vulkanik Kelud dan Pupuk Organik Amandemen
}

\author{
Suntoro'), Hery Widjianto1), Tutik Handayani2)
}

\begin{abstract}
As a result of volcanic eruptions led to the fall of the ash, but there is no much research conducted against nutrient content and the nutrient availability in soil. Disposals of volcanic ash and organic matter are expected fill Mg need in the land. Magnesium In Alfisol is still sufficientless for peanuts. The purpose of this research is study of the impact of volcanic ash and organic fertilizer for the availability and uptake of peanuts $\mathrm{Mg}$ in the Alfisol. The experiments did in a greenhouse used completely randomized design with one factor. Data were analyzed with $\mathrm{F}$ test rate from $95 \%$, and if the treatments showed significant influenced were continued with rate duncan's multiple range test fence from $95 \%$. The observed variables include the levels of chlorophyll, available $\mathrm{Mg}$ and uptake $\mathrm{Mg}$. Research results show that the interaction from treatment chlorophyll content, available $\mathrm{Mg}$ and uptake Mg. Based on the findings of the observations of volcanic ash disposals operating significantly impact the availability of magnesium.
\end{abstract}

Key words : Alfisol, peanut, magnesium, organic matter, volcanic ash

\section{PENDAHULUAN}

Kacang merupakan salah satu yang paling penting tanaman serta tanaman pangan dan tanaman biji minyak dalam dunia. Menurut Sun et al. (2015) Kacang (Arachis hypogaea L.) dibudidayakan di 24,6 juta ha dengan total produksi 41,3 juta ton dan produktivitas 1.676 $\mathrm{kg} /$ ha pada 2012 adalah andalan untuk penghidupan jutaan petani kecil yang berada di daerah tropis dari dunia khususnya di Asia dan Afrika. Sebagian besar produksi kacang tanah di dunia tumbuh sebagian besar di bawah kondisi tadah hujan di mana curah hujan yang tidak diperkirakan dan tidak cukup atau kekeringan serius mempengaruhi produksi kacang tanah (Thai et al. 2014). Konsumsi kacang tanah sebagai sumber pangan nasional terus meningkat. Menurut Silahoy (2012) upaya peningkatan produktivitas kacang tanah tidak bisa hanya menggantungkan diri pada hasil kacang tanah yang ditanam di lahan sawah, tetapi lahan kering atau tegalan memiliki peluang yang dapatdikembangkan sebagai penghasil kacang tanah yang potensial. Lahan kering sebagai media media tumbuh kacang

1)Lecturer Staff of Study Program of Agrotechnology, Faculty of Agriculture, Sebelas Maret University (UNS) on Surakarta.

2) Undergraduate Student of Study Program of Agrotechnology, Faculty of Agriculture, Sebelas Maret University (UNS) on Surakarta.

Contact Author: tutik_uns@yahoo.com tanah mempunyai beberapa sifat kimia tanah yang kurang menguntungkan bagi pertumbuhan dan hasil, terutama ketersediaan sehingga kandungan basa banyak yang tercuci dan bereaksi masam. Kandungan basa yang mengalami pencucian antara lain adalah Magnesium.

Alfisol sangat potensial untuk pengembangan budidaya tanaman. Alfisol merupakan tanah yang relatif muda,masih banyak mengandung mineral primer yang mudah lapuk,mineral liat kristalin dan kaya unsur hara. Tanah ini mempunyai kejenuhan basa tinggi, KTK dan cadangan unsur hara tinggi. Alfisols termasuk tanah yang masih muda dan perkembangan tanah belum lama, sehingga kandungan bahan organik dan unsur hara dalam tanah kurang tersedia, maka solumnya dangkal $(10-15 \mathrm{~cm})$ dari permukaan dan di bawahnya merupakan lapisan batuan

(Ispandi et al 2004). Menurut Purwanto et al. (1997) Magnesium adalah salah satu unsur yang berpengaruh terhadap pertumbuhan tanaman. Magnesium merupakan unsur hara mikro yang dibutuhkan dalam jumlah yang sedikit. budidaya tanaman pangan jarang dilakukan pemupukan $\mathrm{Ca}$ dan $\mathrm{Mg}$ mengakibatkan semakin rendahnya kationkation basa.

Upaya untuk meningkatkan kandungan hara petani memberikan pupuk kandang ke tanah. Menurut Mayadewi et al. (2007) pupuk kandang adalah salah satu pupuk organik yang memiliki kandungan hara yang memiliki kandungan hara yang dapat mendukung kesuburan tanah dan pertumbuhan mikroorganisme dalam tanah. Pemberian 
pupuk kandang selain dapat menambah tersedianya unsur hara, juga dapat mendukung pertumbuhan mikroorganisme serta maupun memperbaiki struktur tanah. Pupuk kandang memiliki sifat alami dan tidak merusak tanah. Pupuk kandang menyediakan unsur makro serta unsur mikro.

Pemanfaatan lingkungan yang digunakan adalah adanya penambahan amelioran. Amelioran adalah bahan yang dapat meningkatkan kesuburan tanah melalui perbaikan kondisi fisik dan kimia. Pemberian bahan amelioran seperti pupuk organik, tanah mineral, zeolit, dolomit,fosfat alam, pupuk kandang, kapur pertanian, abu sekam, dan abu vulkanik dapat meningkatkan $\mathrm{pH}$ tanah dan basa-basa tanah. Debu vulkanik yang menjadi lumpur bahkan memiliki nilai $\mathrm{pH}$ yang lebih rendah, yaitu 3,81 yang tergolong masam. Tanah yang bercampur debu vulkanik (tanah lapisan atas) tergolong masam dengan nilai $\mathrm{pH}$ 4,83. Bahan abu yang digunkan adalah abu kelud. Abu Kelud berukuran lebih halus sehingga lebih mudah untuk mengikat air. Abu Kelud bisa dimanfaatkan untuk menyuburkan tanah dan pertanian. Abu Kelud ini juga memiliki kandungan Fe (besi), Mn (mangan), Si (silikat), Al (aluminium), $\mathrm{Ca}$ (kalsium), K (kalium), dan P (fosfor), jadi abu kelud menjadi pupuk cadangan jangka panjang.

Berdasarkan uraian diatas, maka penelitian ini dilakukan untuk mengkaji pengaruh pemberian abu kelud dan pupuk kandang terhadap ketersediaan serapan unsur Mg pada tanaman kacang tanah

\section{BAHAN DAN METODE}

Penelitian merupakan percobaan rumah kaca dengan menggunakan tanah alfisol dari lahan percobaan Fakultas Pertanian Jumantono Universitas Sebelas Maret Surakarta Jawa Tengah yang dilakukan bulan Agustus 2015 sampai Februari 2016. Bahan abu vulkanik gunung kelud dari abu vulkanik yang jatuh di daerah Solo yang berjarak 200 $\mathrm{Km}$ sebelah barat laut dari pusat Vulkanik, dan pupuk kandang pada kondisi kering udara dicampur dengan $6,5 \mathrm{~kg}$ tanah lapisan atas kering udara (ukuran $<2 \mathrm{~mm}$ ) yang sudah diayak dan kemudian dimasukan ke dalam polibag Percobaan disusun menurut rancangan acak lengkap (RAL). Panen dilakukan pada saat pertumbuhan vegetatif tanaman kacang tanah mencapai pertumbuhan maksimum. Pengamatan yang dilakukan meliputi, berat biomasa kering (kering oven $70^{\circ} \mathrm{C}$ selama \pm 40 jam) hingga berat konstan.Kandungan $\mathrm{Mg}$ dalam biomasa tanaman kacang tanah ditetapkan dengan destruksi basah menggunakan $\mathrm{HNO} 365 \%$ dan $\mathrm{HClO} 470 \%$, dan analisis tanah setelah percobaan meliputi $\mathrm{Mg}$ dapat ditukar (ekstrak NH4-OAc pH 7,0), dengan Atomic Absoption Spektrofotometer(AAS) (Kim, 1996; Puslitanak, 1998). Data hasil pengamatan dianalisis dengan analisis ragam $5 \%$ untuk mengetahui pengaruh dosis pupuk kandang, ketebalan abu kelud, dan Mg. Bila hasil uji terdapat beda nyata maka dilakukan uji lanjutan dengan DMRT (Duncan's Multiple Range Test) taraf $5 \%$, untuk membandingkan rerata antar kombinasi perlakuan.

\section{HASIL DAN PEMBAHASAN}

\section{Pengaruh Perlakuan terhadap Kadar Klorofil}

Hasil analisis ragam terhadap kandungan klorofil menunjukkan bahwa penambahan abu kelud dan pupuk kandang yang digunakan berpengaruh nyata $(p<0.001)$. Berdasarkan uji DMRT taraf $95 \%$ menunjukkan penambahan abu vulkanik dan bahan organik tidak berbeda nyata dengan T. Hal ini ini berkaitan dengan kadar magnesium yang diserap. Menurut Subandi (2008), unsur N, Mg, Fe merupakan unsur-unsur pembentuk dan katalis dalam sintesis klorofil.

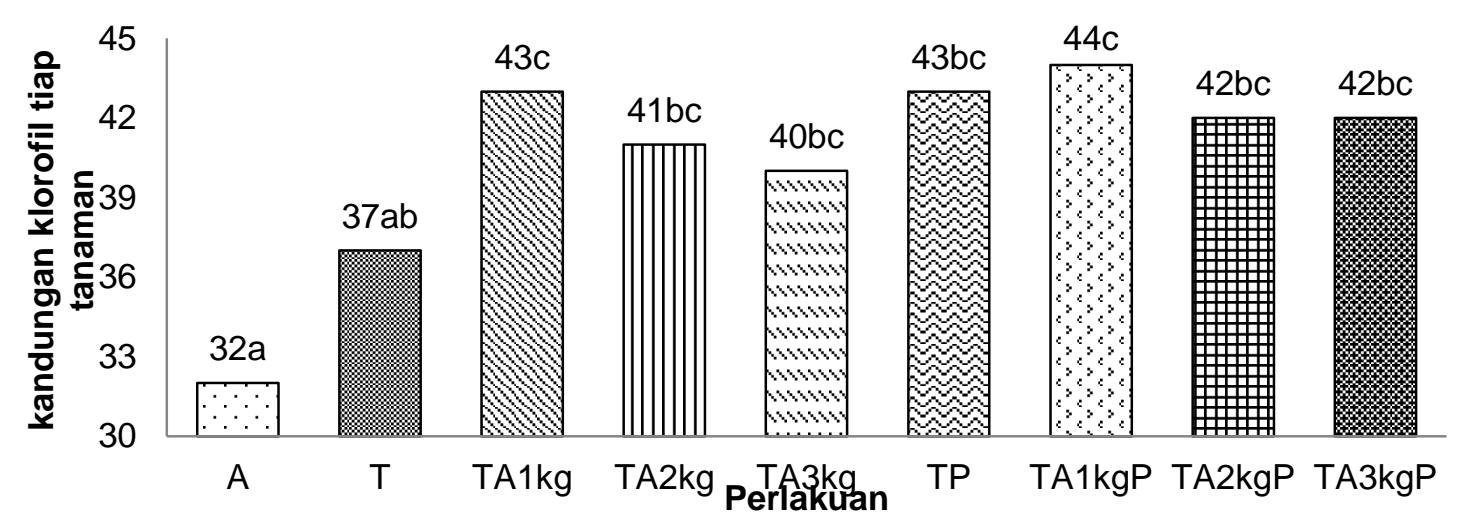

Gambar 2. Pengaruh Perlakuan terhadap Kadar Klorofil kacang tanah 
Peningkatan berat abu vulkanik dari $1 \mathrm{~kg}$ sampai dengan $3 \mathrm{~kg}$ ternyata menghasilkan kandungan klorofil yang semakin menurun yaitu 43 , 41, dan 40 satuan unit. Hal ini juga terlihat pada perlakuan peningkatan berat abu vulkanik dari $1 \mathrm{~kg}$ sampai dengan $3 \mathrm{~kg}$ disertai penambahan bahan organik 5 ton/ $\mathrm{Ha}$ menunjukkan hasil yang menurun yaitu 44,42 , dan 42 satuan unit. Peningkatan abu vulkanik tanah+abu vulkanik berat $1 \mathrm{~kg}+\mathrm{BO} 5$ ton/ $\mathrm{Ha}$ (TA1P) mampu meningkatkan kandungan klorofil lebih tinggi dan berbeda nyata dengan $\mathrm{T}$.

Menurut Wahyuni et al.(2012), unsur hara dalam abu vulkanik berkolerasi dengan $\mathrm{pH}$ yang cenderung asam sehingga dapat menurunkan kesuburan tanah. Konsentrasi nutrisi yang terlalu tinggi dapat menyebabkan respon fisiologi pada tanaman seperti halnya respon terhadap salinitas yaitu terjadinya penurunan pertumbuhan, jumlah daun yang lebih sedikit dan tampilan tanaman yang pendek (Kanget al.2011). Konsentrasi nutrisi yang tinggi dapat menurunkan kecepatan transpirasi, hantaran stomata (stomata conductance) dan evapotranspirasi. Menurut Maggio et al. (2007) penurunan pertumbuhan tanaman berkaitan dengan penurunan hantaran stomata (stomata conductance). Kandungan klorofil mengalami peningkatan oleh adanya pengaruh kandungan mineral seperti $N, P, K, S$, $\mathrm{Ca}$, dan Mg (Umar, 1994). Hal ini sesuai dengan penelitian Rothermund (1956) yaitu bertambahnya jumlah kandungan klorofil dalam tanaman berhubungan erat dengan penambahan unsur $\mathrm{Mg}$ yang dikarenakan atom pusat klorofil adalah $\mathrm{Mg}$.

\section{Pengaruh Perlakuan Terhadap Ketersediaan Mg}

Hasil analisis ragam terhadap $\mathrm{Mg}$ tertukar menunjukkan bahwa perlakuan penambahan abu kelud dan pupuk kandang yang digunakan berpengaruh nyata $(p<0.001)$. Berdasarkan uji DMRT taraf $95 \%$ menunjukkan penambahan abu vulkanik dan bahan organik berbeda nyata dengan $\mathrm{T}$. Hal ini diduga pemberian unsur hara dan pemupukan menyebabkankan kandungan $\mathrm{Mg}$ tertukar didalam tanah meningkat. Menurut Hakim et al. (1986) pupuk kandang menambah tersedianya unsur hara bagi tanaman yang dapat diserapnya dari dalam tanah karena kandungan unsur hara dalam pupuk kandang yang lengkap. Berdasarkan hasil korelasi antara serapan magnesium dan nilai $\mathrm{pH}$ menunjukan nilai yang rendah $(r=0,24)$ dimana dengan kenaikan $\mathrm{pH}$ akan menurunkan ketersediaan $\mathrm{Mg}$ jika $\mathrm{pH}$ melewati netral. Menurut Hanafiah (2007) $\mathrm{pH}$ optimum untuk ketersediaan unsur hara tanah adalah netral karena semua unsur hara makro tersedia secara maksimum

Menurut Hakim et al.(1986), ketersediaan magnesium dapat terjadi akibat proses pelapukan mineral-mineral yang mengandung magnesium. Ketersediaan magnesium bagi tanaman akan berkurang pada tanah-tanah yang mempunyai kemasaman tinggi dan diendapkan menjadi mineral sekunder pada kondisi $\mathrm{pH}$ basa. $\mathrm{Ca}$ dan $\mathrm{Mg}$ dapat mengurangi efek kemasaman tanah dan dapat membantu unsur hara lain yang terjerap menjadi tersedia bagi pertumbuhan tanaman.

Hubungan $\mathrm{Mg}$ tersedia tanah dengan kadar klorofil dalam daun tanaman (Gambar 5) menunjukan hubungan yang linear. Adanya pengaruh interaksi antara penambahan bahan organik dan dolomit terhadap ketersediaan $\mathrm{P}$, $\mathrm{Ca}$ dan $\mathrm{Mg}$, penambahan dolomit akan meningkatkan total klorofil menyebabkan adanya suplai $\mathrm{Mg}$ dari dolomit sehingga mampu meningkatkan ketersediaan $\mathrm{Mg}$ tanah dan serapan $\mathrm{Mg}$ tanaman. Magnesium berperan sangat penting didalam sintesis klorofil sebagai inti klorofil (Suntoro 2003).

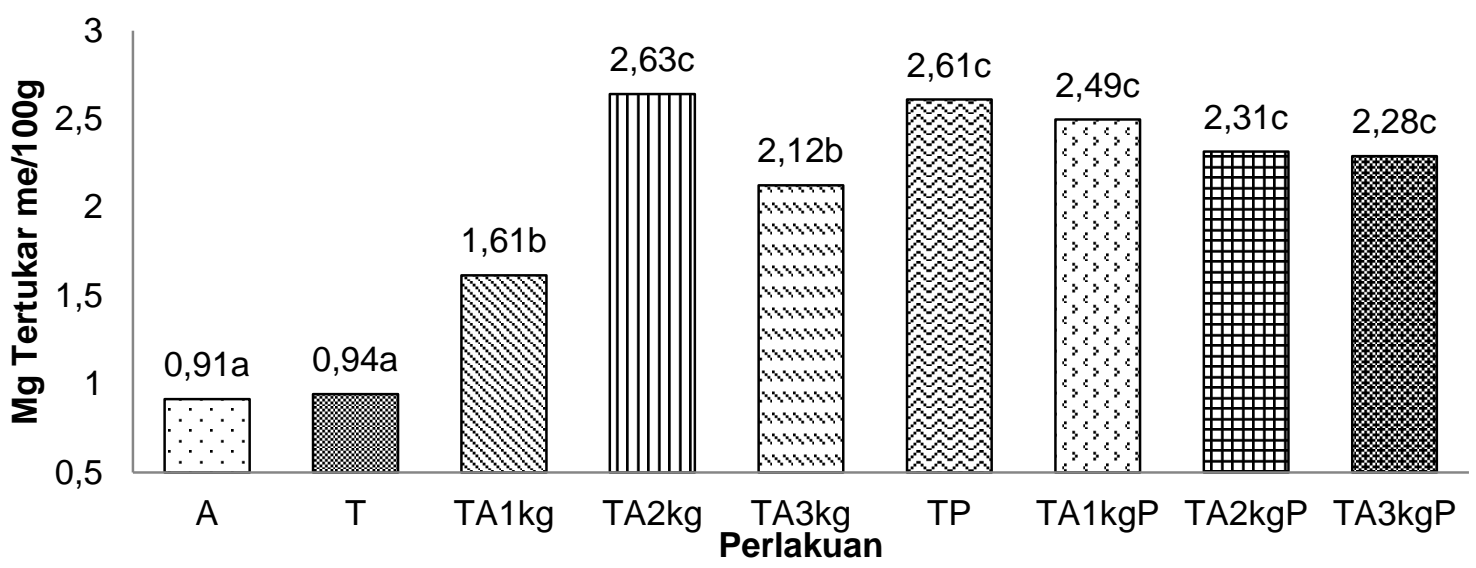

Gambar 3. Pengaruh Perlakuan terhadap Ketersediaan Magnesuim

Ketersediaan dan Serapan Mg Kacang Tanah Alfisol dengan Abu Vulkanik ....... 


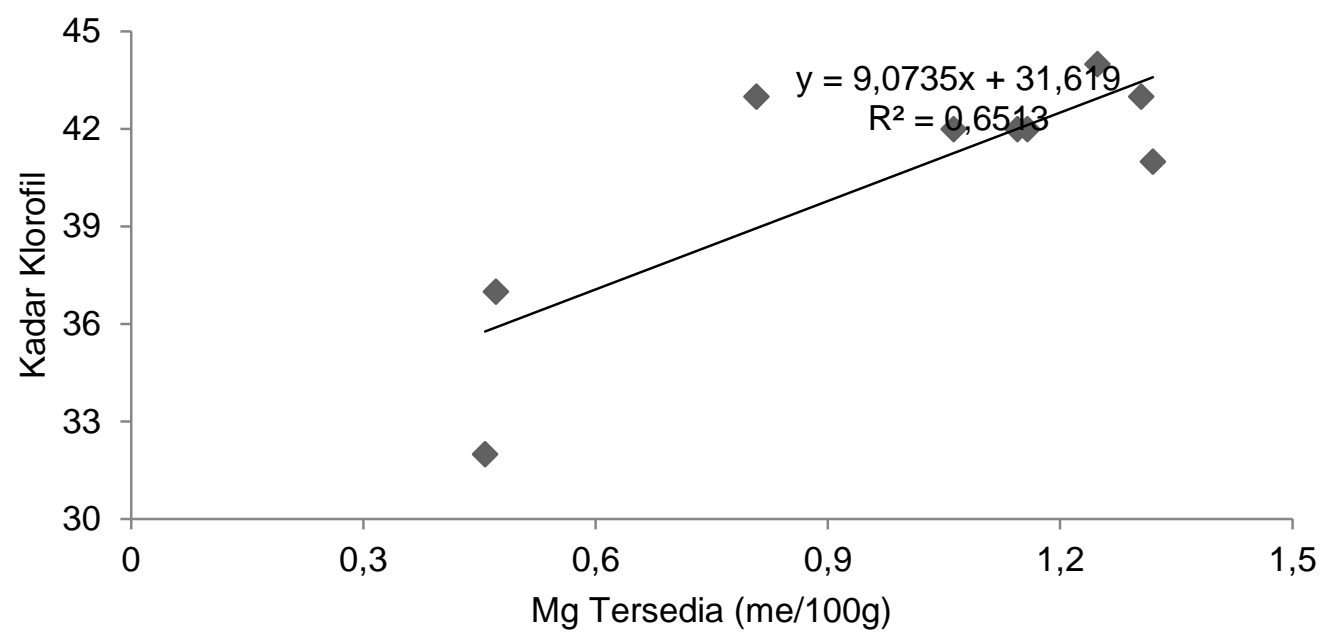

Gambar 5. Hubungan ketersediaan Mg-dapat ditukar tanah Alfisol dan kadar klorofil kacang tanah

\section{Pengaruh Perlakuan terhadap Serapan Mg}

Magnesium diambil/ diserap oleh tanamana dalam bentuk $\mathrm{Mg}^{2+}$. Kadar dan serapan unsur hara essensial berbagai tanaman sangat bervariasi. Hal ini dikarenakan adanya perbedaan serapan unsur hara bagian vegetatif dan generatif tanaman. Penghitungan serapan hara tanaman secara kualitatif dengan cara berat kering tanaman dikalikan dengan nilai jaringan tanaman.

Hasil analisis ragam terhadap serapan Mg menunjukkan bahwa perlakuan penambahan abu kelud dan pupuk kandang yang digunakan berpengaruh nyata $(p<0.005)$ terhadap serapan $\mathrm{Mg}$ kacang tanah. Pemberian abu vulkanik Kelud mempuyai kandungan hara yang cukup baik sebagai penyedia unsur hara tanaman.

Berdasarkan uji DMRT taraf $95 \%$ menunjukkan penambahan abu vulkanik tidak berbeda nyata dengan $\mathrm{T}$, diduga karena terjadinya penurunan serapan $\mathrm{Mg}$ yang disebabkan oleh semakin meningkatnya ketersedian $\mathrm{K}$ dalam tanah. Menurut Fisher et al.(1993), serapan magnesium dipengaruhi oleh perbandingan nisbah $\mathrm{Mg}: \mathrm{K}$, nisbah Ca:Mg:K menurun menyebabkan penurunan serapan $\mathrm{Mg}$ dan $\mathrm{Ca}$. Proses penyerapan unsur hara $\mathrm{Mg}$ berhubungan erat dengan meningkatnya kadar klorofil, dimana meningkatnya kandungan klorofil daun sehinggga fotosintesis tanaman juga meningkat sehingga penyerapan unsur hara semakin meningkat

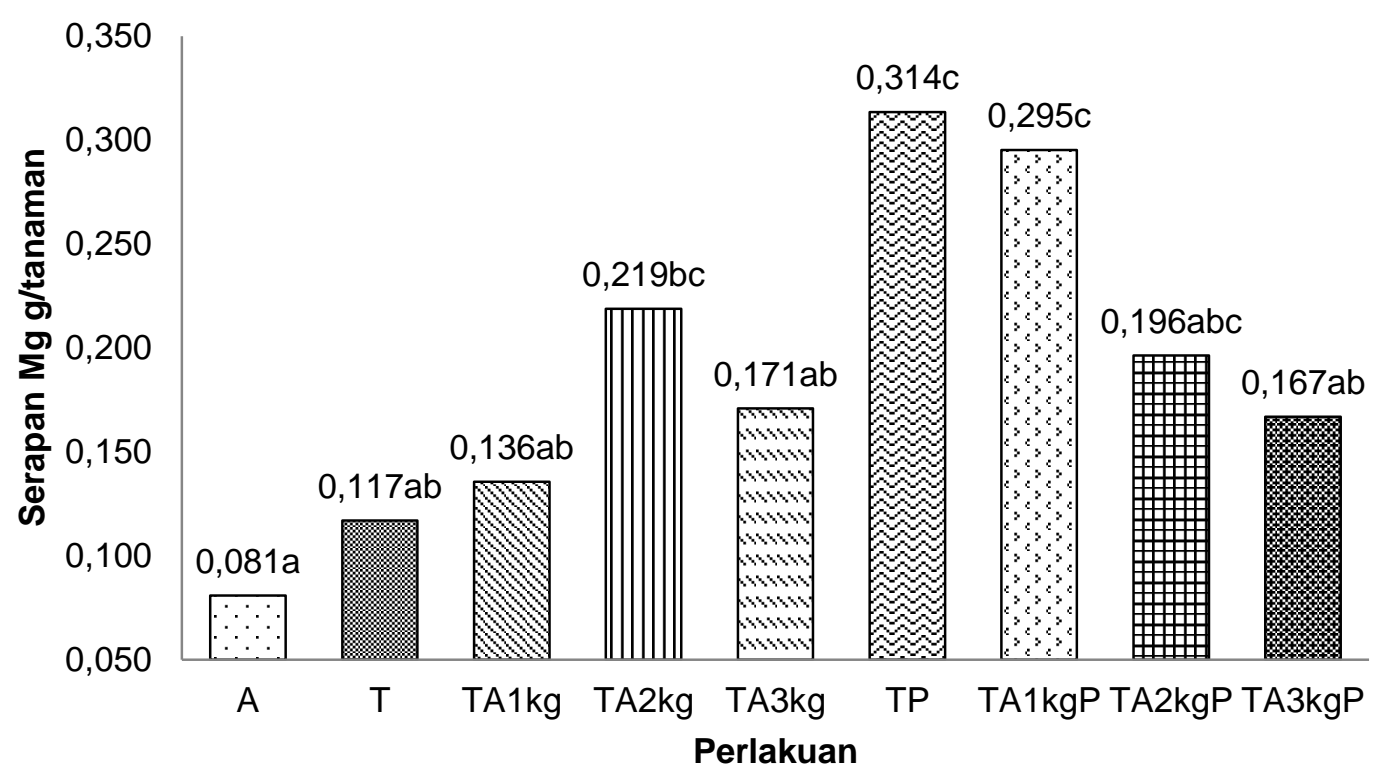

Gambar 6. Pengaruh Perlakuan terhadap Serapan Magnesuim 


\section{Kesimpulan}

Pemberian abu vulkanik Kelud dan pupuk kandang terhadap ketersediaan dan serapan Magnesium di tanah Alfisol menunjukkan hasil yang meningkat dibandingkan dengan perlakuan tanah. Pemberian abu vulkanik Kelud dan kombinasi antara abu vulkanik Kelud dan bahan organik meningkatkan $\mathrm{Mg}$ tersedia dengan hasil yang paling tinggi pada abu + berat abu $2 \mathrm{~kg}$ $\left(1,32\right.$ me $\left.100 \mathrm{~g}^{-1}\right)$. Pemberian abu vulkanik Kelud dan kombinasi antara abu vulkanik Kelud dan bahan organik meningkatkan serapan $\mathrm{Mg}$ pada tanah+bahan organik (13, $06 \mathrm{~g} /$ tanaman) dan tanah+abu $1 \mathrm{~kg}+$ bahan organik $(12,30$ g/tanaman). Respon tanaman kacang tanah terhadap penambahan Abu Kelud dan Pupuk kandang meningkatkan kadar klorofil, jumlah bintil akar, berat brangksan basah, pH, KTK, Mg tertukar, Mg jaringan, dan serapan Mg.

\section{DAFTAR PUSTAKA}

Adam, F., BL., Moore, 1983, Chemical Factors Affecting Root Growth In Subsoil Horizons Of Coastal Plain Soils, Soil Sci Soc Am J, $47 \quad$ : $99-102, \quad$ DOI : 10.2136/sssaj1983.036159950047000/002 $0 \mathrm{x}$.

Brady, NC., Colwell, WE. 1945, Yield and Quality of Large-Seeded type Peaanut as Affected by Potasium and Certain Combination Of Potasium, Magnesium and Kalsium, Am Aoc Agronom J, 36(6) : 429-442.

Hakim, NM., Yusuf, AM., Lubis, SG., Nugroho, M., Rusdi, M., Amin, Go Ban Hong, HH., Bailey, 1986, Dasar-dasar Ilmu Tanah, Bandar Lampung : Universitas Lampung.

Hanafiah, 2007, Dasar-Dasar Ilmu Tanah, Jakarta : Grafindo Persada.

Hartatik, W., LR., Widowati, 2010, Pupuk Kandang,

http://www.balittanah.litbang.deptan.go.id, Diakses tanggal 23 mei 2016

Hendriyani, IS., N., Setiani, 2009, Kandungan Klorofil dan Pertumbuhan Kacang Panjang (Vigna sinensis) pada Tingkat Penyediaan Air yang Berbeda, J Sains and Mat, 17(3) : 145-150, ISSN. 08540675.

Kang, YI., Park, JM., Kim, SH., Kang, NJ., Park, KS., Lee, SY., Jeong, BR. 2011, Effect of Root Zone $\mathrm{PH}$ and Nutrient Concentration on The Growth and Nutrient Uptake of Tomato Seedlings, Journal of Plant Nutrition, 34, DOI : 640-652. 10.1080/01904167.2011.540621.
Maggio, AG., Raimondi, A., Martino, S., De Pascale, 2007, Salt stress response in tomato beyond the salinity tolerance threshold, Environmental and Experimental Botany, 59 : 276-282.

Mayadewi, Ari, 2007, Pengaruh jenis pupuk kandang dan jarak tanam terhadap pertumbuhan gulma hasil jagung manis, Agritrop, 26 (4) : 153-159, ISSN. 02158620.

Priyono, Sarwono, 2015, Pengaruh Dosis Pupuk Organik dan Bobot Abu Vulkan Kelud terhadap Hasil Kangkung Darat (Ipomea reptans L.poir) pada Tanah Regosol, J Agronomika, 10(1) : 1-10.

Rosmarkam, A., NW., Yuwono, 2002, IImu Kesuburan Tanah, Yogyakarta : Kanisius.

Rothermund, P. 1956, Hemin And ChlorophyllThe Two Most Important Pigmen For Life On Earth, The Ohio Journal Of Science, 56 (4).

Shoji, S., Takahashi, T. 2002, Environmental and Agricultural Significance of Volcanic Ash Soils, J Soil Sci Plant Nutr, 73 : 113-135.

Silahoy, 2012, Efek Dolomit Dan Sp-36 Terhadap Bintil Akar, Serapan N Dan HasilKacang Tanah (Arachis hypogaea L.) Pada Tanah Kambisol, Agrologia, 1(2) : 91-98, ISSN. 2301-7287.

Sudaryo, Sutjipto, 2009, Identifikasi dan Penentuan Logam BeratPada Tanah Vulkanik di Daerah Cangkringan, Kabupaten Sleman dengan Metode Analisis Aktivasi Neutron Cepat. Seminar Nasional V SDM Teknologi, Yogyakarta.

Sun, T., Zhang, Z., Ning, T., Mi Q, Zhang, X., Zhang, S., Liu, Z. 2015, Colored Polyethylene Film Mulches On Weed Control,Soil Conditions And Peanut Yield, Plant Soil Environ, 61(2) : 79-85, DOI : 10.1722/882/2014.pse.

Suntoro, 2003, Peranan Bahan Organik terhadap Kesuburan Tanah dan Upaya Pengelolaan, Surakarta : Sebelas Maret University Press.

Thai Hoang, Kaewpradit Wanwipa, Jogloy S., Vorasoot Nimitr, Patanothai Aran, 2014, Nutrient Uptake Of Peanut Genotypes With Different Levels Of Drought Tolerance Under Midseason Drought, Turkish Journal Of Agriculture And Forestry, 38 : 495-505, DOI. 10.3906/tar-1309-45

Wahyuni, ET., Triyono, S., Suherman, M. 2012, Penentuan Komposisi Kimia Abu Vulkanik dari Erupsi Gunung Merapi. 